\title{
SEISMIC EVALUATION OF MIXED STEEL AND RC COLUMNS IN HYBRID HIGH-RISE BUILDINGS
}

\begin{abstract}
D.-P. N. KONTONI ${ }^{1}$, A. A. FARGHALY ${ }^{2}$
The growth in high-rise building construction has increased the need for hybrid reinforced concrete and steel structural systems. Columns in buildings are the most important elements because of their seismic resistance. Reinforced concrete (RC) columns and steel columns were used herein to form hybrid structural systems combining their distinct advantages. Eleven 3D building models subjected to earthquake excitation with reinforced concrete beams and slabs of 12 floors in height and with different distributions of mixed columns were analyzed by the SAP2000 software in order to investigate the most suitable distributions of a combination of reinforced concrete and steel columns. Top displacements and accelerations, base normal forces, base shear forces, and base bending moments were computed to evaluate the selected hybrid structural systems. The findings are helpful in evaluating the efficiency of the examined hybrid high-rise buildings in resisting earthquakes.
\end{abstract}

Keywords: High-rise buildings, Hybrid RC-steel buildings, RC beams and slabs, RC columns, Steel columns, Seismic response, Earthquake resistant structures.

\section{INTRODUCTION}

Concrete structures can produce stiff systems and provide better damping. This is advantageous when controlling any structural movements, whether seismic or wind-induced. The newer composite systems should be recognized whereby conventional structural steel sections are either filled with or encased in concrete. The overall performance of these types of frames is generally

\footnotetext{
${ }^{1}$ Assoc. Prof., Dr. of Civil Eng., Dipl. Civil Eng., Technological Educational Institute of Western Greece (until 06.05.2019), University of the Peloponnese (since 07.05.2019), Department of Civil Engineering, 1 M. Alexandrou Str., Koukouli, GR-26334 Patras, Greece, e-mail: kontoni@teiwest.gr

${ }^{2}$ Assoc. Prof., Ph.D., Civil. Eng., Sohag University, Department of Civil and Architectural Constructions, Faculty of Industrial Education, Sohag 82524, Egypt, e-mail: farghaly@techedu.sohag.edu.eg
} 
better than either of what the constituent parts could offer individually. The more mass a building has, the more force it develops under seismic ground motion and, hence, acceleration. The performance of any building during an earthquake is largely a function of design rather than only materials used in construction. In the "strong column"/“weak beam" earthquake resistant design approach, a weak point is purposefully placed in the beam near the column. As the building racks and stresses build up, the "weak point" goes plastic and prevents more damage to the joint. The beam still remains connected to the column, though it can rotate a considerable amount without damaging the connection. Therefore, the strong column/weak beam design allows engineers to essentially place a "fuse" in their structures which will "blow" when it becomes overloaded.

Elnashai and Broderick (1994) [1] studied experimentally the behavior of partially encased composite beam-columns under the combined effects of earthquake and axial loads in a series of cyclic and pseudo-dynamic tests, and their excellent performance was demonstrated, and thus their applicability to the earthquake-resistant design of multi-storey structures was reaffirmed.

Shanmugam and Lakshmi (2001) [2] reviewed the behavior of steel-concrete composite columns with emphasis on experimental and analytical work accounting for the effects of local buckling, bond strength, seismic loading, confinement of concrete, and secondary stresses.

Chan (2001) [3] presented a computer-based optimization technique for the design of tall hybrid mixed steel and concrete buildings.

Hadianfard et al. (2012) [4] investigated the behavior of steel columns subjected to blast loading and proved that the column sections and their elastic-plastic properties and boundary conditions are very important in resisting blast loading.

Esmaeili et al. (2013) [5] studied the seismic behavior of dual structural systems in forms of steel moment-resisting frames accompanied with either reinforced concrete shear walls or with concentrically braced frames, and showed that the system based on steel moment-resisting frames accompanied with reinforced concrete shear walls has a higher ductility and response modification factor and has more advantages over the other.

Cao et al. (2013) [6] studied experimentally full-scale simply supported steel sheeting-styrofoamconcrete composite sandwich slabs with different shear connectors and concluded that the longitudinal slippery is limited and therefore these new composite sandwich slabs have high sagging bending resistance and good ductility.

Kvedaras et al. (2015) [7] studied thin-walled steel tubes filled with concrete beams and their effect on increasing the bending capacity of the sections and presented a method for design which was 
found to be in good agreement with the results of the carried out experimental, numerical, and theoretical investigations.

Xiao et al. (2017) [8] presented an experimental study on the behavior of concrete-encased composite columns with multi-separate steel sections subjected to axial and eccentric loads and the test results indicated that full composite action between the concrete and the steel sections can be achieved even though the steel sections do not connect with one another.

Buyuktaskin (2017) [9] analyzed (through FEM) and compared two multi-storey steel buildings subjected to earthquake excitation, one with eccentrically steel braced frames and the other with core and shear walls, and concluded that the dual system decreased construction costs by $34 \%$ when compared to the multi-storey steel building.

The development in high-rise construction has increased the demand for innovative structural design solutions in which hybrid reinforced concrete and steel configurations are used.

Bompa and Elghazouli (2014) [10] examined the load transfer mechanisms in hybrid structural systems consisting of steel columns connected to reinforced concrete beams by means of embedded shear-keys which are directly welded to the steel columns and fully embedded in the reinforced concrete beams, with a focus on the development of improved assessment and design procedures.

Bompa and Elghazouli (2015) [11] examined experimentally the shear transfer mechanisms and ultimate behavior of hybrid systems consisting of reinforced concrete beams connected to structural steel columns and proposed modifications to the existing analytical approaches for conventional reinforced concrete elements in order to provide a reliable evaluation of the ultimate shear capacity of such hybrid systems.

Bompa and Elghazouli (2016) [12] investigated the structural performance of hybrid members consisting of reinforced concrete flat slabs (both with and without shear reinforcement) connected to steel columns by means of fully integrated shear-heads.

Moharram et al. $(2017,2018)$ [13,14] investigated experimentally and numerically the inelastic behavior of hybrid structural assemblages consisting of reinforced concrete (RC) beams connected to steel columns by means of fully embedded shear-keys.

This paper investigates the ability of mixed reinforced concrete (RC) and steel columns in hybrid high-rise buildings to resist earthquakes by combining the most effective elements of the buildings, such as columns with different kinds of materials ( $\mathrm{RC}$ or steel), and with different distributions to show which model is more suitable for earthquake resistance, where the judgment of the hybrid model decision is based on the values of top lateral displacements, top accelerations, base shear forces, base bending moments, and total weight of the buildings. The RC and steel columns were 
distributed as to best be prepared for earthquake resistance, minimize its destructive effects, and judge the efficiency of the presented hybrid structural systems.

\section{MODEL DESCRIPTIONS}

Eleven 12-storey 3D building models (with each floor measuring $3 \mathrm{~m}$ in height) were analyzed to show the efficiency of hybrid structural systems composed of reinforced concrete beams and slabs, as well as reinforced concrete and steel columns. The basic model was designed to have a square floor plan to neglect the effects of torsion, RC-type columns were chosen as the square crosssection ones, steel columns were chosen as B.F.I.B. (Broad Flange I-Beam, with the width of each flange nearly equal to the depth in the cross-section) to reduce the effects of the stiffening of the model in the depth direction of the I-beam. All models were analyzed by the SAP2000 software [15], the beams and columns were modeled as frame elements (with each element carrying both normal and shear force and a bending moment), and slabs as shell elements with fixed boundary conditions (to transmit the loads from the slabs to the beams).

Figure 1 shows the different distributions of RC and steel columns in the eleven different building models, where the beams and slabs are of the RC type for all models. Figure 1(a) represents the control model (consisting of RC square cross-section columns) against which every other model will be compared. Figure 1(b) represents a model of RC columns inside and steel columns distributed along the perimeter of the model. Figure 1(c) represents a model with all columns steel except the center column which is RC. Figure 1(d) shows a model with $\mathrm{x}$-shape in-plane distribution of steel columns among the rest RC columns. Figure 1(e) shows a model with all steel columns. Figure 1(f) represents a model with inner steel columns and with RC columns distributed along the perimeter of the model. Figure $1(\mathrm{~g})$ shows RC columns along the perimeter and the center with steel columns distributed around the center of the model. Figure 1(h) represents a model with an $\mathrm{x}$-shape in-plane distribution of RC columns among the remaining steel columns. Figure 1(i) shows a staggered distribution of both RC and steel columns. Figure 1(j) represents a model with composite columns (steel B.F.I.B. columns encased in RC). Figure 1(k) shows a model with steel B.F.I.B. columns with staggered webs directions (one in the x-direction and the other in the $y$ direction) to avoid the effect of one direction web and not stiffen the model in one direction only (the web's direction).

Table 1 shows the properties of the members (SAP2000 elements) used in each building model. 
The Egyptian Codes of Practice for loading (ECP-201) [16] for Reinforced Concrete (ECP-203) [17] and for Steel Construction (ECP-205) [18] were adhered to.

A live load for a residential building of $2 \mathrm{kN} / \mathrm{m}^{2}$ is used, while the distributed load on the beams is equal to $4.8 \mathrm{kN} / \mathrm{m}$. The earthquake example applied here was the El-Centro earthquake with an accelerogram as shown in Figure 2, with maximum ground acceleration equal to $0.322 \mathrm{~g}$ and exposure angle equal to $45^{\circ}$.

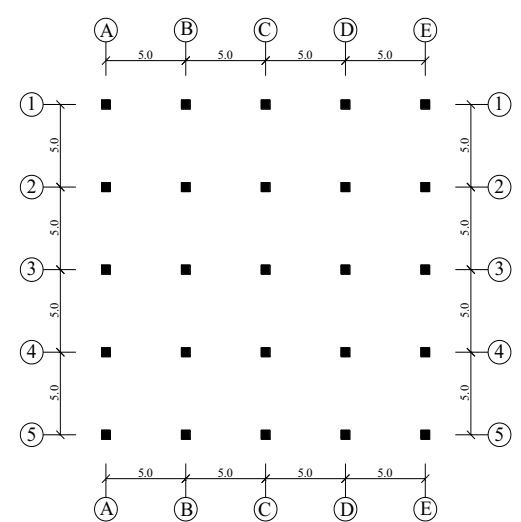

(a) All RC columns (all conc.).

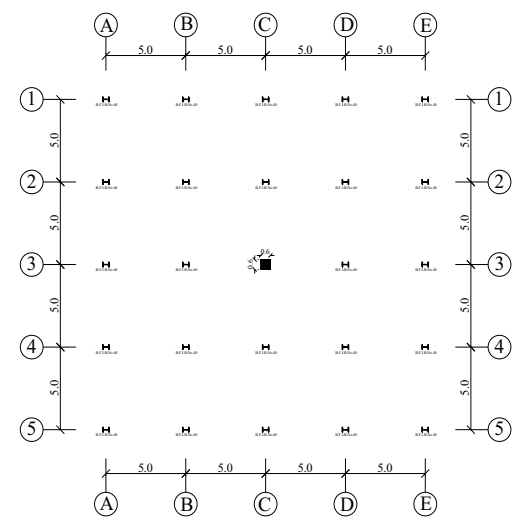

(c) One center RC and outer steel columns (outer 2).

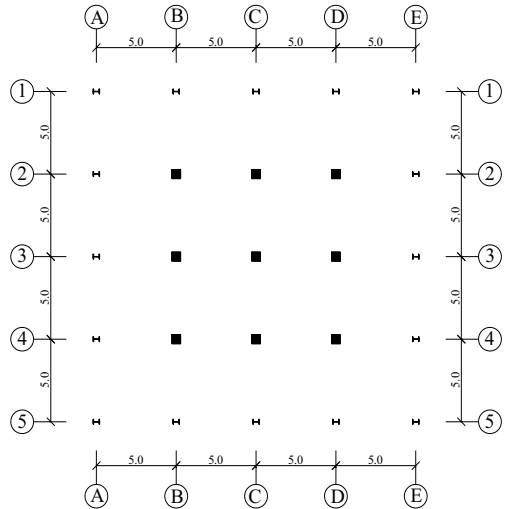

(b) Outer steel columns (outer 1).

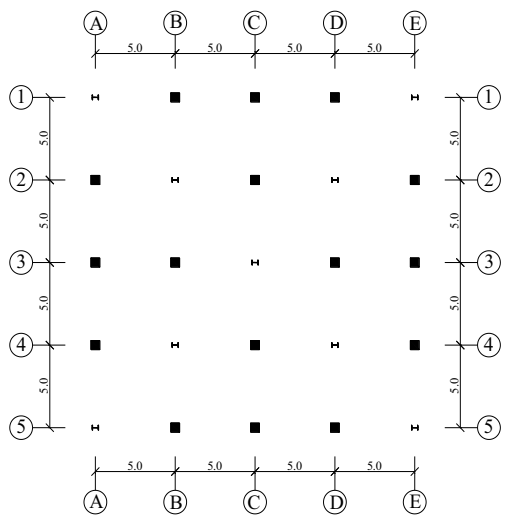

(d) X-shape distribution of steel columns (x-steel). 


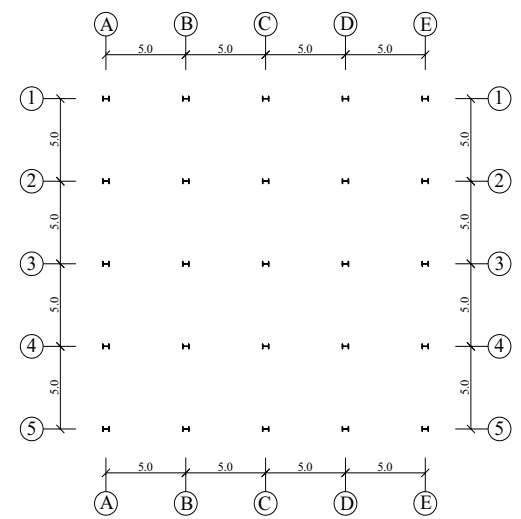

(e) All steel columns (all steel).

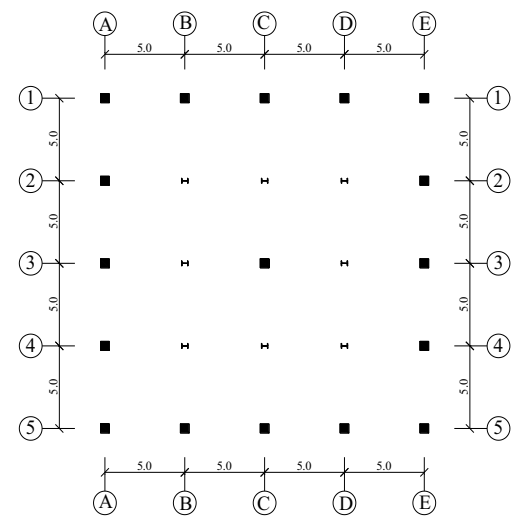

(g) Inner steel columns, and core concrete columns (inner 2).

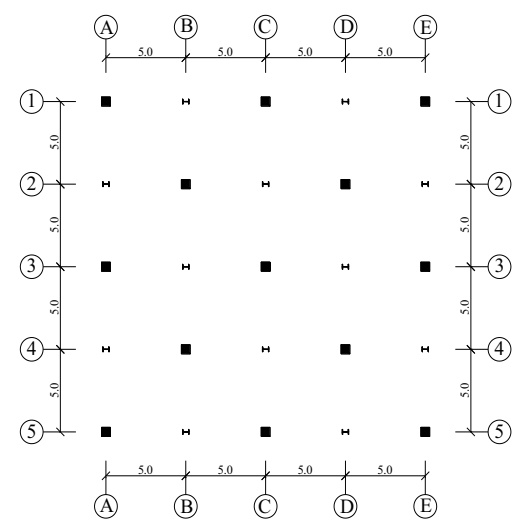

(i) Staggered distribution of steel and RC columns.

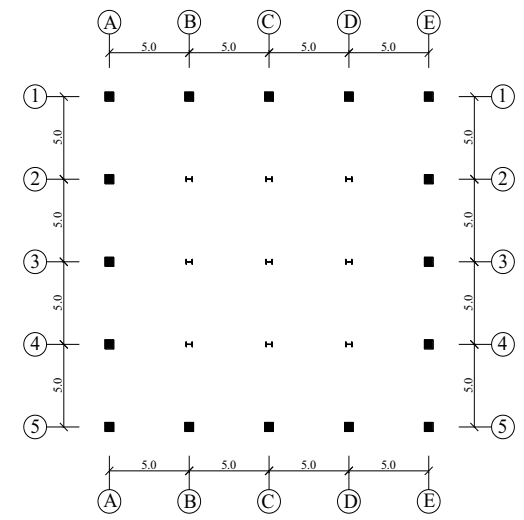

(f) Outer RC columns and inner steel columns (inner 1).

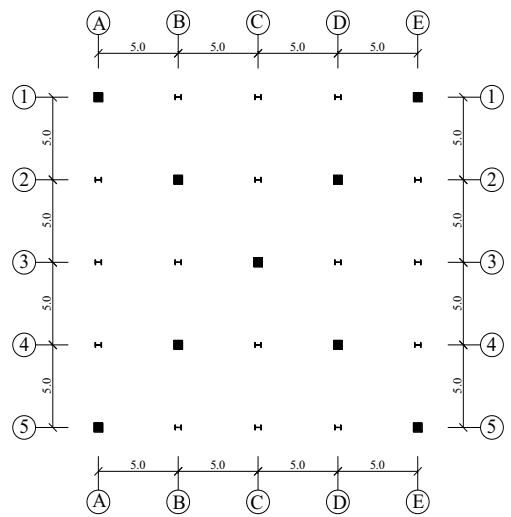

(h) X-shape distribution of RC columns (x-conc.).

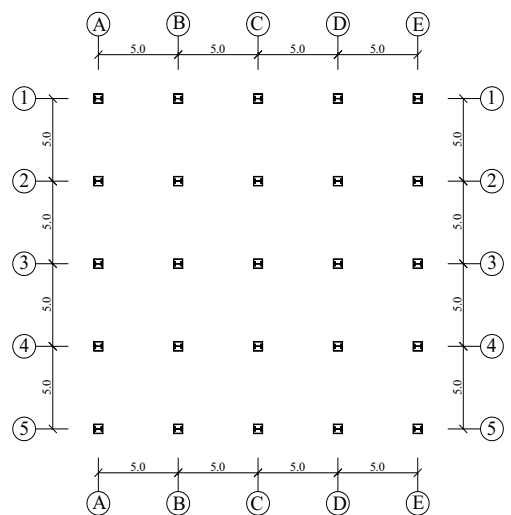

(j) Composite columns sections (comp.). 


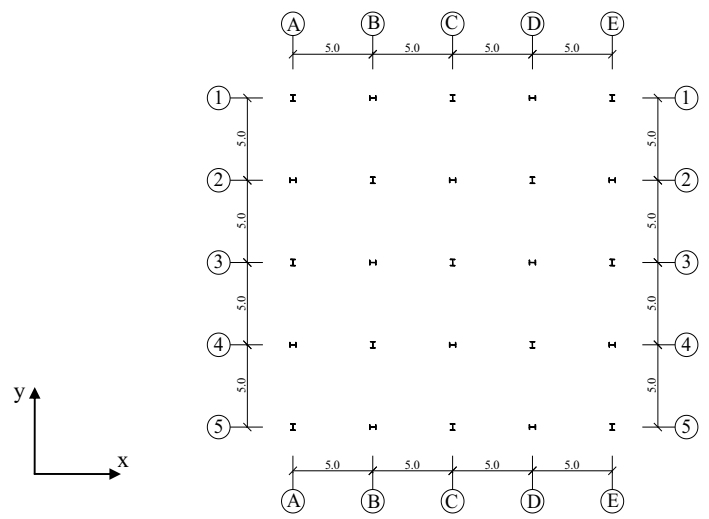

(k) Staggered distribution of steel columns.

Fig. 1. The different distributions of columns in the eleven building models.

Table 1. Properties of the building models

\begin{tabular}{|c|c|c|c|c|c|c|}
\hline Element & $\begin{array}{c}\gamma \\
\left(\mathrm{kN} / \mathrm{m}^{3}\right)\end{array}$ & $\begin{array}{l}\text { Dimension } \\
\quad(\mathrm{mm})\end{array}$ & Reinforcement & $\begin{array}{c}\mathrm{E} \\
\left(\mathrm{kN} / \mathrm{m}^{2}\right)\end{array}$ & $\begin{array}{c}\mathrm{S}_{\mathrm{u}} \\
\text { (ultimate } \\
\text { strength) } \\
\left(\mathrm{kN} / \mathrm{m}^{2}\right) \\
\end{array}$ & $\begin{array}{c}\mathrm{S}_{\mathrm{y}} \\
\text { (yield } \\
\text { strength) } \\
\left(\mathrm{kN} / \mathrm{m}^{2}\right) \\
\end{array}$ \\
\hline $\begin{array}{c}\mathrm{RC} \\
\text { Column }\end{array}$ & 25 & $600 \times 600$ & $22 \phi 16 \mathrm{~mm}$ & $18 \times 10^{6}$ & ------- & ------- \\
\hline Beam & 25 & $250 \times 600$ & $\begin{array}{l}4 \phi 16 \mathrm{~mm} \text { Upper } \\
\text { and } \\
3 \phi 12 \mathrm{~mm} \text { Lower }\end{array}$ & $18 \times 10^{6}$ & ------- & ------- \\
\hline Slab & 25 & thick. 120 & $\begin{array}{c}\text { Mesh } \\
6 \phi 10 \mathrm{~mm} / \mathrm{m}\end{array}$ & $18 \times 10^{6}$ & ------- & ------- \\
\hline $\begin{array}{c}\text { Steel } \\
\text { Column }\end{array}$ & 78.2 & o & ------- & $200 \times 10^{6}$ & $400 \times 10^{3}$ & $250 \times 10^{3}$ \\
\hline
\end{tabular}

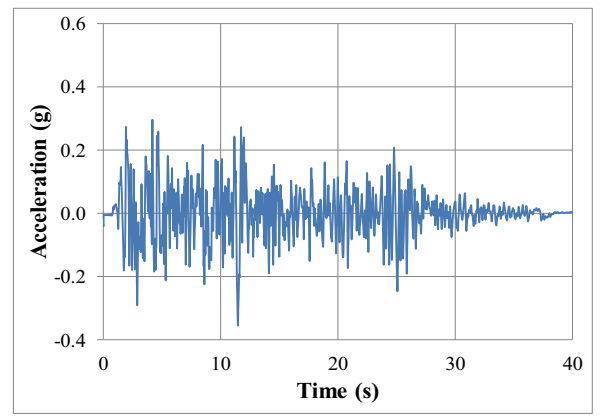

Fig. 2. The El-Centro earthquake accelerogram. 


\section{RESULTS AND DISCUSSION}

In total, the eleven 12-storey 3D building models (with each floor measuring $3 \mathrm{~m}$ in height) present in Figure 1 were analyzed via SAP2000 to show the efficiency of dual hybrid structural systems composed of reinforced concrete beams and slabs, as well as reinforced concrete and steel columns. Top displacements and accelerations, base normal forces, base shear forces, and base bending moments were computed to evaluate the chosen structural systems, and the time history maximum values are presented herein.

Figure 3 shows the top lateral displacements in the $\mathrm{x}$ - and $\mathrm{y}$ - directions for different distributions of columns across the various models. The lateral top displacements in the $\mathrm{x}$-direction have larger values in the cases of: "all RC" columns, the "outer 1", the $\mathrm{x}$-shape distributed steel columns (among RC ones), the composite columns, and the staggered mixed columns, all due to the heavier weight of all these models, while the rest of the cases are nearly equal, except for the case of the staggered steel column model, where the lowest displacement was recorded because of the high stiffness of the model due to the staggered webs of B.F.I.B. in both directions and the lower weight of the model.

The lateral top displacements in the y-direction have maximum values in the cases of: all RC columns, the "outer 2", all steel columns (unidirectional webs: all webs are in the x-direction, and the y-direction is the weak web axis), and the composite columns. The smaller values of the lateral y-direction displacements are seen in cases "outer 1", "inner 1", and "inner 2", because the webs of steel columns are in the $\mathrm{x}$-direction and the number of steel columns is higher than that of the RC columns. The lateral top displacements in the $\mathrm{y}$-direction for the $\mathrm{x}$-shape distributed steel or $\mathrm{x}$-shape distributed RC column cases are nearly equal, indicating the effect of the mixed system between RC and steel columns in both distribution and their overall number. Finally, the top displacements in the y-direction for staggered mixed (steel and RC) columns and staggered steel columns are nearly equal, which means that the effect of stiffening the model with steel and RC columns is equal in the $\mathrm{y}$-direction since the steel columns are directed in such a way as to give a similar effect in the $y$ direction as that of the $\mathrm{RC}$ columns in the model. 


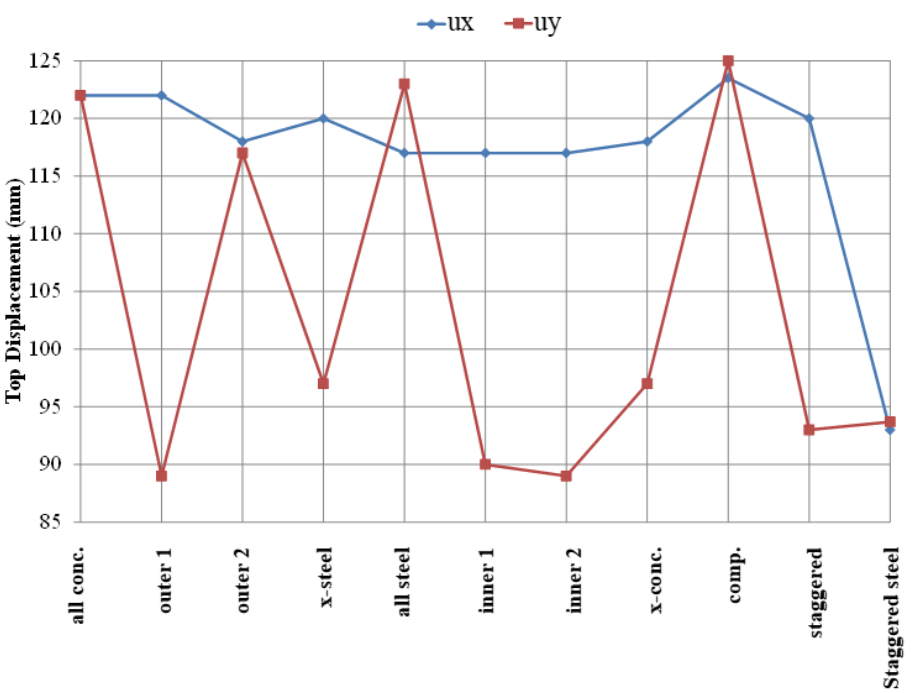

Columns cases

Fig. 3. Top lateral displacements in the $\mathrm{x}$ - and $\mathrm{y}$-directions for different distributions of columns.

Figure 4 represents the top accelerations in the $\mathrm{x}$ - and $\mathrm{y}$-directions for different distributions of the columns in the building models. The top y-acceleration is less than the top x-acceleration for all models except for composite and "all RC" columns models. The high values of acceleration demonstrate the high stiffness of the model. The stiffness is higher in composite section columns than in all RC columns in both the $\mathrm{x}$ - and $\mathrm{y}$-directions. The $\mathrm{x}$-direction acceleration shows similar values for almost all models, while in the steel staggered column model the lowest value (reduced by almost 1.2 times when comparing to the rest of the models) was recorded. For y-direction acceleration, the "outer 2" and "all steel" cases show similar behavior, the "outer 1", "inner 1", "inner 2", and staggered models show similar behavior, and both the x-shape distributed steel and $\mathrm{RC}$ columns show roughly similar behavior. 


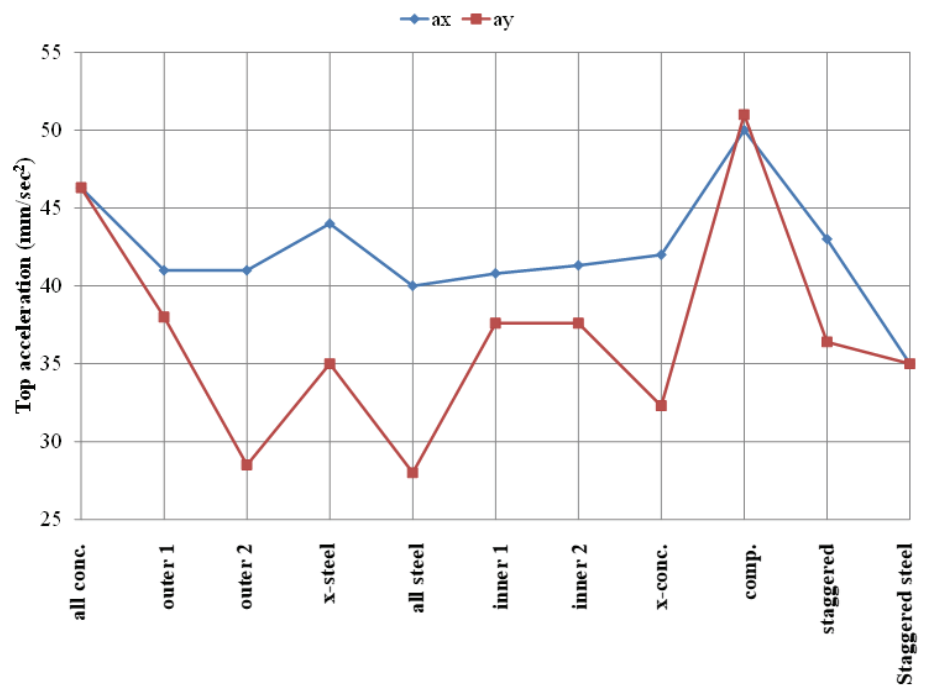

Columns cases

Fig. 4. Top accelerations in the $\mathrm{x}$ - and $\mathrm{y}$-directions for different distributions of columns.

Figure 5 shows the base normal forces for different distributions of the columns across the building models. The greatest value of normal force is seen in the case of the composite column model (where the columns carry 1.15 more than the RC columns), and the lowest value of normal force is in the staggered steel case (1.13 lower than the RC column cases). The "outer 2" and "all steel" model cases are 1.06 times lower than the RC column model.

Figure 6 represents the base shear forces in the $\mathrm{x}$ - and $\mathrm{y}$-directions for models with different distributions of the columns in the building models. The base shear forces in the y-direction are lower than the corresponding values in the $\mathrm{x}$-direction (since the strong axes of the B.F.I.B. web steel sections are in the $\mathrm{x}$-direction), the higher values of the base shear force are seen in the cases of "all RC" and composite columns; most base shear force values in the y-direction are close, but in the case of "all steel" columns, the base shear force shows the lowest value, and, in most cases, the ratios between the base shear and the "all RC" and composite column cases equal nearly 1.6 and 1.8 , respectively. The base shear in the $\mathrm{x}$-direction is larger than in the $\mathrm{y}$-direction for different the distributions of columns, though most cases show comparable values, except in the "all RC" and composite column cases, where the ratios between the mean values of the base shear force in the $\mathrm{x}$ direction and the "all RC" and composite columns are nearly 1.13 and 1.3, respectively. The "all 
RC" and "composite" column cases represent the highest values of base shear forces in both the xand y-directions.

Figure 7 represents the base bending moments in the $\mathrm{x}$ - and $\mathrm{y}$-directions for models with different distributions of the columns. Bending moment $\mathrm{M}_{\mathrm{x}}$ is less than $\mathrm{M}_{\mathrm{y}}$ for all cases of columns distributions. The bending moments in the x-direction for "outer 2" and "all steel" cases record the lower values (the low ability of these configuration cases to resist earthquake loads), while for "all RC" and "composite" cases the bending moments record higher values. The bending moments in the y-direction for all distribution patterns are rather close, except for the "all RC" and "composite" column cases, where the ratios between most cases and the "all RC" and "composite" cases are equal to almost 1.1 and 1.5 , respectively.

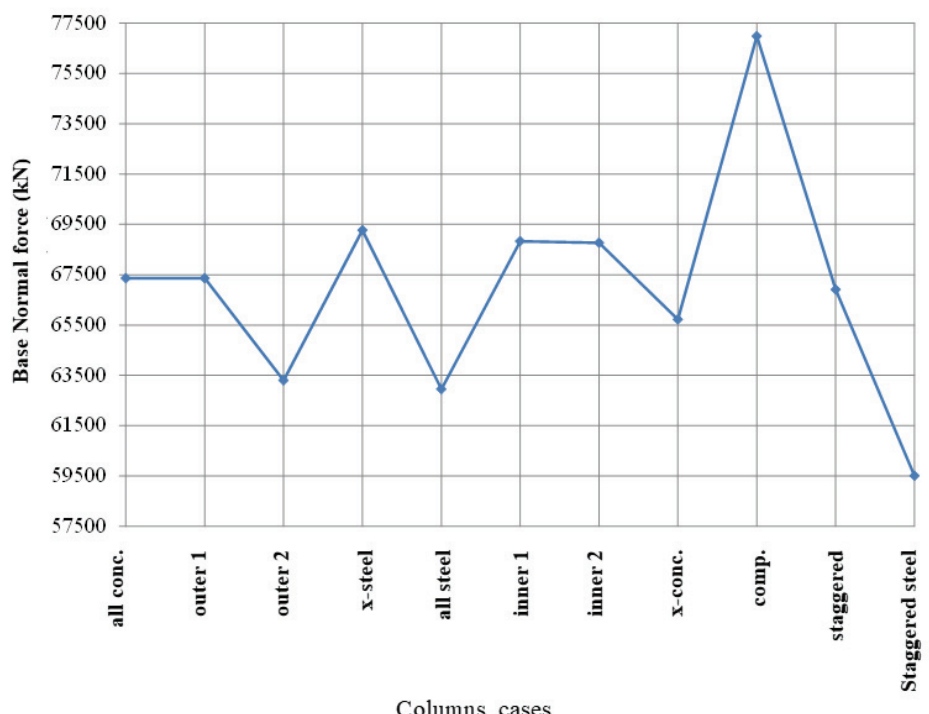

Fig. 5. Base normal forces for different distributions of columns. 


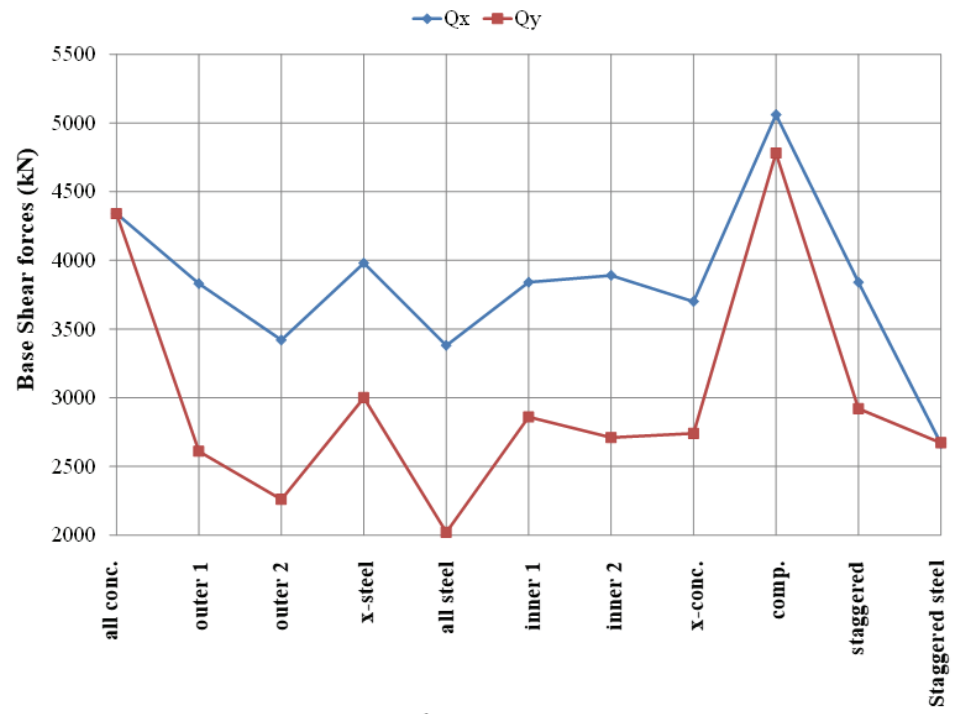

Columns cases

Fig. 6. Base shear forces in the $\mathrm{x}$ - and $\mathrm{y}$-directions for different distributions of columns.

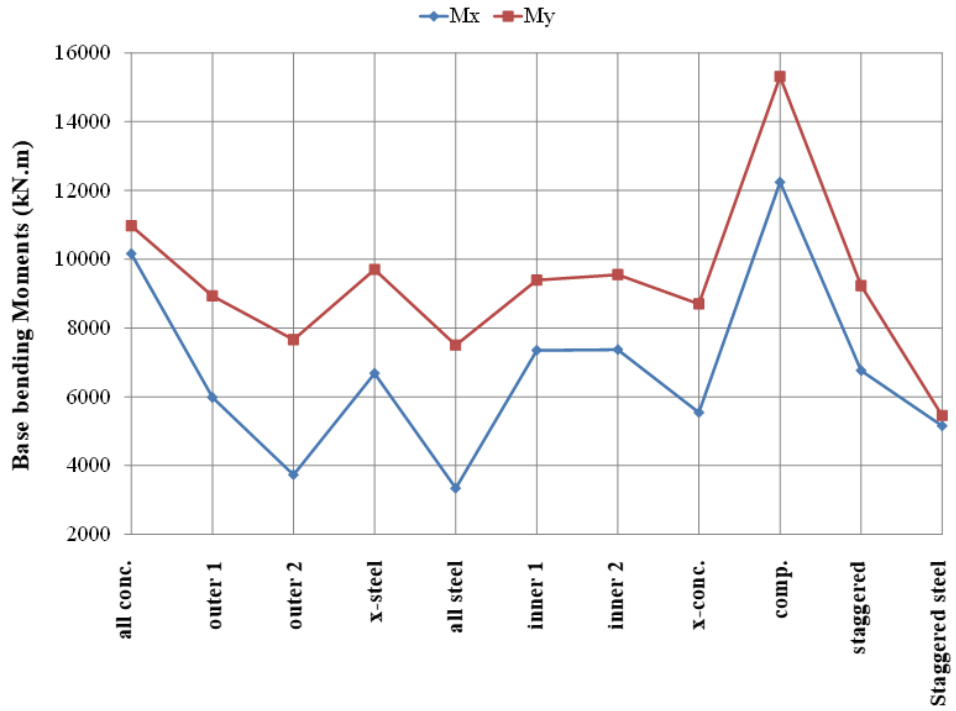

Columns cases

Fig. 7. Base bending moments in the $\mathrm{x}$ - and $\mathrm{y}$-directions for different distributions of columns. 


\section{Conclusions}

The development of high-rise building construction has increased the need for structural design solutions in which hybrid steel and reinforced concrete distributions are used. In this paper, various arrangements of reinforced concrete columns and steel columns were used to form hybrid structural systems combining their distinct advantages.

Three-dimensional high-rise building models consisting of reinforced concrete slabs and beams, and having various mixed steel and reinforced concrete column distributions were subjected to earthquake excitation and then analyzed via the SAP2000 software in order to investigate the most suitable arrangement of mixed steel and reinforced concrete columns. Eleven 3D building models with RC beams and slabs with various column distribution patterns (hybrid systems of mixed RC and steel columns with different arrangements) were investigated to study the seismic performance of these models.

In order to properly judge these hybrid systems, the models were subjected to an earthquake and the top lateral displacements, top lateral accelerations, base normal forces, base shear forces, and base bending moments were computed, and comparisons were made between the control case (all RC columns) and the different configuration cases of mixed RC and steel columns. The following conclusions can be drawn:

- Differential and irregular vertical displacements in the same plane in the case of RC with steel columns at the same floor level (related to different column material response under seismic load) may cause a redistribution of forces in the structural components.

- $\mathrm{RC}$ columns provide more of the damping effect than steel ones.

- Vaccination of a reinforced concrete column system with steel columns is useful in raising the efficiency of seismic resistance of reinforced concrete structures.

- The effect of the light weight of steel columns used in building models helps to reduce the seismic response of hybrid RC buildings.

- A hybrid system of mixed RC and steel columns is helpful in supporting structures found in seismic zones.

- $\mathrm{RC}$ and composite section columns give the maximum base shear forces and base bending moments.

- Steel columns give the minimum base shear forces and base bending moments. 


\section{REFERENCES}

1. A. S. Elnashai, B. M. Broderick, "Seismic Resistance of Composite Beam-Columns in Multi-Storey Structures", Part 1: Experimental Studies. Journal of Constructional Steel Research 30(3): 201-229, 1994. DOI: https://doi.org/10.1016/0143-974X(94)90001-9.

2. N. E. Shanmugam, B. Lakshmi, "State of the art report on steel-concrete composite columns", Journal of Constructional Steel Research 57(10): 1041-1080, 2001. DOI: https://doi.org/10.1016/S0143-974X(01)000219.

3. C.-M. Chan, "Optimal lateral stiffness design of tall buildings of mixed steel and concrete construction”, The Structural Design of Tall and Special Buildings, 10(3): 155-177, 2001. DOI: https://doi.org/10.1002/tal.170.

4. M. A. Hadianfard, A. Farahani, A. B-Jahromi, "On the effect of steel columns cross sectional properties on the behaviours when subjected to blast loading", Structural Engineering and Mechanics 44(4): 449-463, 2012. DOI: https://doi.org/10.12989/sem.2012.44.4.449.

5. H. Esmaeili, A. Kheyroddin, M. A. Kafi, H. Nikbakht, "Comparison of nonlinear behavior of steel moment frames accompanied with RC shear walls or steel bracings", The Structural Design of Tall and Special Buildings 22(14): 1062-1074, 2013. DOI: https://doi.org/10.1002/tal.751.

6. P. Z. Cao, Y. F. Lu, K. Wu, "Experimental research on sagging bending resistance of steel sheeting-styrofoamconcrete composite sandwich slabs", Steel and Composite Structures 15(4): 425-438, 2013. DOI: http://dx.doi.org/10.12989/scs.2013.15.4.425.

7. A.K. Kvedaras, G. Sauciuvenas, A. Komka, E. Jarmolajeva "Analysis of behaviour for hollow/solid concretefilled CHS steel beams", Steel and Composite Structures 19(2): 293-308, 2015. DOI: https://doi.org/10.12989/scs.2015.19.2.293.

8. C. Xiao, F. Deng, T. Chen, Z. Zhao, "Experimental study on concrete-encased composite columns with separate steel sections", Steel and Composite Structures 23(4): 483-491, $2017 . \quad$ DOI: https://doi.org/10.12989/scs.2017.23.4.483.

9. A. H. A. Buyuktaskin, "A study on the comparison of a steel building with braced frames and with RC walls", Earthquakes and Structures 12(3): 263-270, 2017. DOI: https://doi.org/10.12989/eas.2017.12.3.263.

10. D. V. Bompa, A. Y. Elghazouli, "Force Transfer Mechanisms between Steel Columns and RC Beams by means of Shearkeys", Proceedings of Eurosteel 2014: 7th European conference on steel composite structures, Naples, Italy, 10-12 September, Paper No. 03-476, pp. 1-6, 2014.

11. D. V. Bompa, A. Y. Elghazouli, "Ultimate shear behaviour of hybrid reinforced concrete beam-to-steel column assemblages", $\quad$ Engineering $\quad$ Structures 101 : $318-336, \quad 2015 . \quad$ DOI: http://dx.doi.org/10.1016/j.engstruct.2015.07.033.

12. D. V. Bompa, A. Y. Elghazouli, "Structural performance of RC flat slabs connected to steel columns with shear heads", Engineering Structures 117: 161-183, $2016 . \quad$ DOI: https://doi.org/10.1016/j.engstruct.2016.03.022.

13. M. I. Moharram, D. V. Bompa, A. Y. Elghazouli, "Experimental and Numerical Assessment of Mixed RC Beam and Steel Column Systems", Journal of Constructional Steel Research 131: 51-67, 2017. DOI: https://doi.org/10.1016/j.jcsr.2016.12.019.

14. M. Moharram, D. Bompa, and A. Elghazouli, "Inelastic Assessment of Hybrid RC Beams to Steel Column Configurations Using Structural Steel Shear-Keys”, In: Hordijk D., Luković M. (eds), High Tech Concrete: Where Technology and Engineering Meet (Proceedings of the 2017 fib Symposium, held in Maastricht, The Netherlands, June 12-14, 2017), Springer, Cham, pp. 1336-1343, 2018. DOI: https://doi.org/10.1007/978-3319-59471-2 154 .

15. SAP2000® Version 17. Integrated Software for Structural Analysis and Design; Computers and Structures, Inc.: Walnut Creek, CA, USA; New York, NY, USA, 2015.

16. ECP-201. Egyptian Code of Practice for Calculating Loads and Forces in Structural Work and Masonry, ECP201. Housing and Building National Research Center, Ministry of Housing, Utilities and Urban Planning, Cairo, Egypt, 2008.

17. ECP-203. Egyptian Code of Practice for Design and Construction of Reinforced Concrete Structures, ECPCS203. Housing and Building National Research Center, Ministry of Housing, Utilities and Urban Planning, Cairo, Egypt, 2007.

18. ECP-205. Egyptian Code of Practice for steel construction, Load and Resistance Factor Design (LRFD), ECP205. Housing and Building National Research Center, Ministry of Housing, Utilities and Urban Planning, Cairo, Egypt, 2008. 


\section{LIST OF FIGURES AND TABLES:}

Fig. 1. The different distributions of columns in the eleven building models.

Fig. 2. The El-Centro earthquake accelerogram.

Fig. 3. Top lateral displacements in the $\mathrm{x}$ - and $\mathrm{y}$-directions for different distributions of columns.

Fig. 4. Top accelerations in the $\mathrm{x}$ - and $\mathrm{y}$-directions for different distributions of columns.

Fig. 5. Base normal forces for different distributions of columns.

Fig. 6. Base shear forces in the $\mathrm{x}$ - and $\mathrm{y}$-directions for different distributions of columns.

Fig. 7. Base bending moments in the $\mathrm{x}$ - and $\mathrm{y}$-directions for different distributions of columns.

Table 1. Properties of the building models.

Received 05.12.2018

Revised 30.06.2019 